\title{
Understanding Children's Independent Mobility Through the Lens of Universal Design: A Case of Delhi, India
}

\author{
Megha TYAGI ${ }^{\mathrm{a}, 1}$ and Gaurav RAHEJA ${ }^{\mathrm{a}}$ \\ ${ }^{a}$ Department of Architecture \& Planning, Indian Institute of Technology Roorkee, \\ India
}

\begin{abstract}
Children's independent mobility (CIM) is associated with improved physical activity and social competence among children. Despite such benefits, there is a worldwide decline in overall CIM levels, owing to the multi-factors of the insufficient supportive built environment, traffic and negative parental perception. This paper attempts to make a unique case of relooking children's everyday mobility experiences by adopting a universal design (UD) approach. The key objectives are to (i) discuss the global evolution of CIM in comparison to UD from an Indian narrative, (ii) understand CIM though parental concerns and children's perspective, and (iii) develop a shared connection between UD goals and CIM. These objectives were achieved by a desk-based literature review followed by a qualitative pilot study within an urban neighbourhood of Delhi. Focus group discussion with twenty children in the age group of 7-12 years and personal interview sessions with fifteen parents were conducted, which were analysed using content analysis method. The literature suggests that to date, CIM has been majorly looked upon from the twopoint perspective of urban planning and health. Whereas UD provides an opportunity for bringing in the dimension of 'culture' into the discussion. Especially in a culturally diverse country like India, where children and parental discussions reveal concerns of safety, familiarity and proximity to child-specific destinations as a precursor for CIM levels. Overall, this study emphasises that both CIM and UD form a complementary process overarching the aim of empowering children to move freely, promoting their health, social participation and inclusion.
\end{abstract}

Keywords. Children's Independent Mobility, urban neighbourhood, Universal Design, India

\section{Introduction}

Children's independent mobility (CIM), defined as the right of a child to move freely without adult supervision within local surroundings[1], is a crucial concept in creating child-friendly cities. It enables children to explore and become aware of their local surroundings, simultaneously enhancing their cognitive skills[2], environmental competence[3], and emotional connect. It generates a sense of social participation among children by considering them as 'active citizens' of society. However, current findings [4-6] reveal that there exists a decline in CIM levels within global urban contexts. For instance, in United States (US) and United Kingdom (UK), the prevalence of children travelling independently to school or other local destinations has tremendously reduced

${ }^{1}$ Corresponding author, Department of Architecture \& Planning, Indian Institute of Technology Roorkee, India; E-mail: megha.tg@gmail.com 
from $90 \%$ and $80 \%$ in the 1970 s to only $13.5 \%$ and $10 \%$ in the early $2000 \mathrm{~s}[1,7]$. While only $1 / 3^{\text {rd }}$ of children in Hong Kong enjoy independent mobility during their homeschool journeys[8]. Even in India, children do not attain sixty minutes of globally recommended[9] moderate to vigorous physical activity (MVPA) per day[10], indicating a decline in independent mobility practices. Heightened car-dependency, increased distances to child-specific destinations and parental perception of risks to children from traffic and strangers $[11,12]$ are some of the reasons attributed to this decline.

Recent research has demonstrated that there exists a strong correlation between CIM and planning of urban neighbourhood[13]. It is believed that streets and neighbourhood spaces, if designed efficiently, can lead to an increased CIM. However, owing to the heterogeneous and overlapping nature of built environment factors within diverse urban and cultural landscapes, the overall results remain inconsistent[13-15].

Departing from a conventional strategy, this paper examines the issue by taking universal design as a perspective in an Indian context. Universal design (UD) as a concept inherits a basic evolving character that strives to include a diverse set of population. It challenges designers to develop context-specific strategies taking into account the dimension of 'culture' as one of the core foundations[16]. Integrating UD as an inclusive perspective towards CIM further enables a framework for socially inclusive urban environments. This paper extends a qualitative discourse from CIM to UD in an Indian urban neighbourhood based in the capital city of Delhi. The study aims to draw a parallel between two overlapping fields that ultimately seek to achieve universal health, wellness and social participation. The key objectives are to (i) discuss the global evolution of CIM in comparison to UD from an Indian narrative, (ii) understand CIM though parental concerns and children's perspective, and (iii) develop a shared connection between UD goals and CIM.

\section{Background}

The first objective is realised by understanding the fundamental premises of both CIM and UD, along with their position within the existing policy framework of India.

\subsection{The parallel evolution of CIM \& UD}

The concept of CIM began appearing in literature during the early 1990s with a phenomenal work of Hillman et.al.[1] investigating children's daily freedom to travel alone to school in London. This work defined CIM, and since then, several international studies $[17,18]$ across various disciplines began exploring CIM within their local context, adopting the socio-ecological framework[19] as the foundation. This framework recognises CIM as a complex phenomenon resulting from various levels of contextual influences in terms of physical, social and socio-demographic factors[14]. The physical factors which were found to have a significant correlation with CIM include land-use mix, street connectivity, traffic, street characteristics, distance to destination, residential density, degree of urbanisation and proportion of parks or green spaces. It establishes the fact that planning and design of urban neighbourhood has a strong impact on CIM. While the role of parents or caregivers as gatekeepers for children's mobility decisions was identified as a significant factor under social environment aspect. Parental decision to grant freedom to children is believed to be affected by their neighbourhood perception and attitude towards CIM. At the same time, factors of parent's education, profession, 
household income and car ownership were also taken into consideration. Children's variables like age, gender, older sibling and perceived maturity level to travel independently were additionally included in studies for an overall comprehensive understanding of CIM.

On the other hand, it is since the 1950s and 1980s that the roots of UD are traced from the disability rights movements of the US[20] and the Japan government's response towards the challenge of fast-ageing society, respectively[21]. Mace defined and promoted UD in the mid-1980s to communicate a design approach that could be utilised by a wider range of users[20]. Children as users were first acknowledged by Frank Bowe[22] in his work on inclusive teaching methods for children with learning disabilities. This approach resulted in an acclaimed educational framework of Universal Design for Learning (UDL), with practical applications in designing inclusive curriculum, teaching practices and classroom layout. Further, the focus on 'play' as an area of investigation for children with diverse disabilities also received attention. It involved assessment of the existing status of playgrounds[23], indoor play settings[24] and toys[25], resulting in the development of inclusive play design guidelines and tools. Similarly, the work under 'independent mobility' [26] centred around mobility aids and assistive devices, especially for children with mobility impairments. Lately, concerns regarding limited inclusion of the voices of children with disabilities within active school travel and CIM literature[27] has gained momentum, emphasising the need to address this gap by researchers and policymakers.

\subsection{Positioning CIM \& UD in urban policies of India}

India is home to the largest number of children in the world, significantly larger than the number in China[28]. Children in the age group $0-18$ years, constitute $39 \%$ of the country's total population, the majority of which live in urban areas[29]. As one of the signatories of the United Nations Convention on Child Rights (UNCRC) act since 1992, India has prioritised children specific issues in their policy frameworks like the National Policy of Action for Children (NPAC). This policy that came into being in 2005 as a follow-up to the 2002 Special Session on Children of the UN General Assembly was revised in 2016 and is meant to guide and inform laws, plans and programs affecting children's health and protection[30].

On the other hand, recently, India has also identified children as one of the key users of urban infrastructure. The National Institute of Urban Affairs (NIUA), under the Ministry of Urban Development (MoUD), launched the Child-friendly Smart Cities (CFSC) initiative in 2014. Still, at a nascent stage, CFSC recognises mobility and safety as one of the crucial components for creating a child-friendly environment[31]. It focuses on the built environment factors of street connectivity, traffic volume, distance to destination and walkability as vital elements influencing parent's degree of granting more freedom to children's mobility. Likewise, the recent design guidelines for infant, toddler and caregiver-friendly neighbourhood (ITCN) [32] also highlights designing neighbourhood streets as the focus area.

In the same light, India as a signatory to the United Nations Convention on the Rights of Persons with Disabilities (UNCRPD), is committed to making its transportation system accessible and usable by all sections of society. 'Handbook on Barrier-Free and Accessibility' and 'Harmonised guidelines and space standards for the barrier-free built environment for persons with disability and elderly persons' launched by the Indian government in 2014 and 2016 respectively assist in achieving the aim of inclusive 
mobility. The recently launched 'Accessible India' campaign in 2015 by the Ministry of Social Justice and Empowerment (MoSJE) predominantly emphasises conceiving a safe, accessible and inclusive mobility environment across cities. The Rights of Persons with Disabilities Act, 2016 (RPwD) enforces the ideas of non-discrimination for all within diverse built environment, including mobility.

\section{Methods}

\subsection{Study context}

The second objective of the study is based on a pilot study conducted in a typical urban neighbourhood of Delhi. It is one of the world's largest megacities, with a population density of 11,297 persons per square kilometre[33] and a total population of 1,10,34,555 persons(census 2011). In terms of planning, despite various urban policies and master plans, a significant part of Delhi remains unplanned[34]. Out of seven typologies of such unplanned settlements, 567 neighbourhoods come under the category of 'regularised unauthorised' colonies, which were developed on agricultural land with illegal means but were later regularised by the government in the late 1970s[35]. This study situates itself in one such typical example of 'regularised unauthorised colony' of 'Panchwati, Adarsh Nagar' under North West MCD (Municipal Corporation of Delhi) area. The neighbourhood is located near 'Azadpur Mandi' (Asia's largest wholesale fruits and vegetable market), which experiences heavy vehicular traffic leading to congested road networks throughout the day. Planned in early 1960, the gated neighbourhood comprises of 79 residential plots with a central 2000 sq. m. park; housing a total of 60 families. Figure 1 shows the land-use map of the neighbourhood showing locations of nearest transport stations. The housing typology can be categorised as semi-detached low-rise structures. Besides residential plots, the neighbourhood also comprises of a primary level government school, a private bank, two private grocery shops and a temple. Figure $2 \&$ 3 shows children cycling and playing in the neighbourhood.

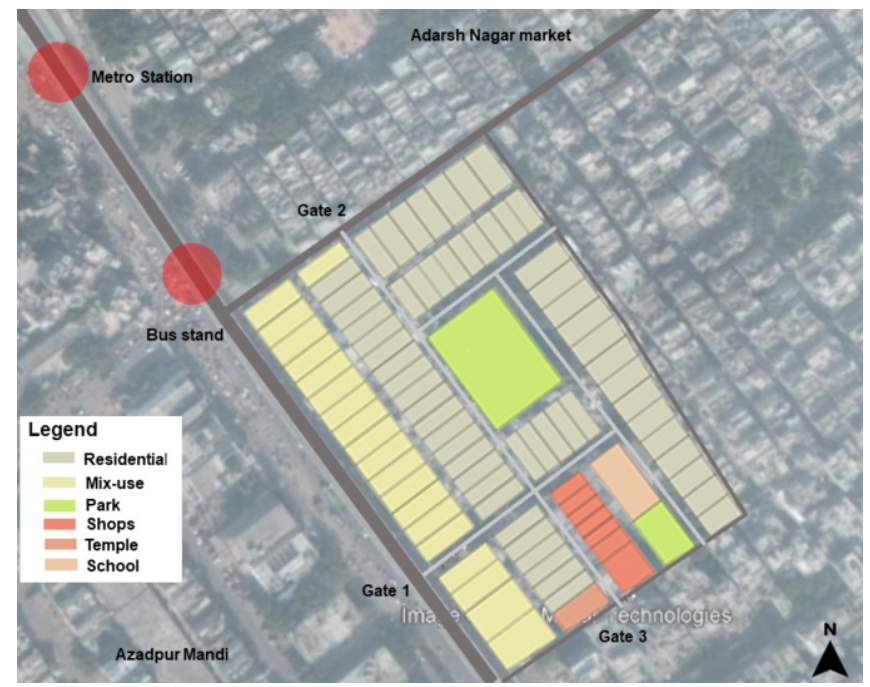

Figure 1. Land-use map of the neighbourhood 


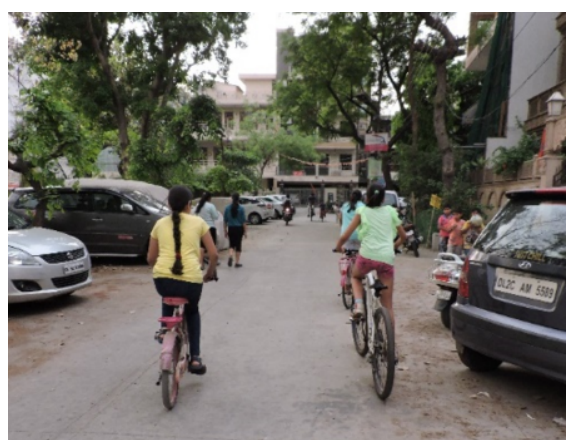

Figure 2. Children cycling in the neighbourhood

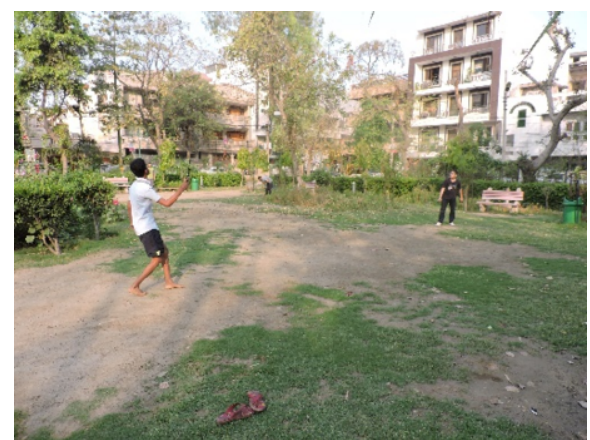

Figure 3. Children playing inside the neighbourhood park

\subsection{Participants}

The inclusion criteria for participants were children aged 7-12 years and their parents, who were contacted via phone call or e-mail obtained through the neighbourhood's resident welfare association (RWA) officials. The multiple international[1, 4] and national study[36] protocols, as well as psychological theories[37], guided the selection of this age group, establishing the fact that children in middle childhood are most physically active and can easily navigate through their local surroundings. Based on this criterion, a total of 37 families were approached, out of which 15 families agreed to participate. Overall, one parent (mother/father) each from these 15 participating families and twenty children were finalised for the study.

\subsection{Data collection and analysis}

Individual semi-structured interview sessions were conducted with parents in their respective homes (in the absence of their children). Parents reported on open-ended questions related to their child's mode of transport, accompaniment status to school and local destinations and the reasons for the same. Parent's personal information related to their educational qualification, profession, family type, their child's age and gender was already noted at the beginning of the session. On the other hand, focus group discussion (FGD) was employed for children to gain insights from their opinions about neighbourhood and CIM. Both the interview and FGD sessions were conducted in the participant's language of preference (English and Hindi), lasting for approximately 20 minutes and one hour, respectively. Their responses were recorded by a voice recorder, which was transcribed verbatim. Content analysis was conducted for each answer using NVivo 12 pro. Coding categories and sub-categories were identified by reviewing the transcripts based on the aim of the study.

\section{Findings}

\subsection{Parental concerns about CIM}

Table 1 provides the descriptive characteristics of the participants. From the table, it was clear that the majority of participating parents were homemakers, with $80 \%$ of them living in a joint family system (parents, children, grandparents and sometimes cousins 
with aunt and uncle living in the same house). The content analysis revealed a total of three themes from parent's interview: (1) children's safety and security; (2) neighbourhood travel license, and (3) school travels.

Table 1. Descriptive characteristics of participating children and parents

\begin{tabular}{ccc}
\hline Characteristic & Number $(\mathbf{N})$ & $\%$ \\
\hline Child's gender & 10 & 50 \\
Boy & 10 & 50 \\
Girl & & \\
Child's age & 8 & 40 \\
7-9 Years & 12 & 65 \\
10-12 Years & & 27 \\
Farent's & 4 & 73 \\
Mother & 11 & 40 \\
Parent's education & 6 & 60 \\
Post Graduate & 9 & 20 \\
Graduate & 3 & 80 \\
Parent's Profession & 12 & 80 \\
Working & & 20 \\
Non-Working & 12 & \\
Family Type & 3 & \\
Joint & & \\
Nuclear & &
\end{tabular}

\subsubsection{Children's safety and security}

Fear from strangers $(92 \%)$ was found to be the main concern of children travelling to school or moving independently within the neighbourhood. Traffic and distance to destination, along with poor infrastructure, were found to be the secondary factors. A majority of parents $(70 \%)$ limit their children's outdoor mobility to evenings, citing reasons of more people taking a walk in the evening who might keep an eye on their children. Such behaviour was a clear example of a positive 'informal social control' among parents.

"I feel very safe for my kids (within neighbourhood gates). Even if I have to go somewhere in the evening for 2-3 hours, there is no tension with my kids moving alone within local areas, since this society is safe and I have many friends having kids in the same age group keeping an eye on them. That is why it is very convenient". (mother of a 10-year old boy)

Constant surveillance was hugely supported by parents $(90 \%)$, especially for a female child. Parents with a female child were quite vocal in expressing their concerns regarding the same owing to the increase in media reports concerning physical abuse of girls in Delhi. As a consequence, one of the parents had allowed her 12-year daughter to drive a two-wheeler within the neighbourhood as a practice for her future independent mobility, considering it safer than cycling or walking. 


\subsubsection{Neighbourhood travel licenses}

A total of four local non-school destinations were identified for children: (i) Tuition class (55\%); (ii) hobby class (20\%); (iii) structured sports class (10\%) and (iv) outdoor free play $(90 \%)$. The daily trip of more than half of participating children to tuition class was majorly characterised as dependent and active since parents (mostly mothers) used to accompany their child daily on foot for both side journey. While, in case of hobby and structured sports class, due to lack of nearby options, parents were compelled to daily drive their children to faraway places, thus making this trip dependent and highly motorised. The other reason was a complete lack of trust in public transport among parents. Delhi Metro, a major successful public transport with an entire coach reserved for women and children, was not perceived safe by parents for children's independent travelling. Majority of them (60\%) reported metro as safe for children above 16 years of age. Lack of last-mile connectivity, stranger danger, the presumption of child's incompetence to navigate within the metro system and crowd are the reasons cited for the same. The other destination of outdoor free play is independent and active since the location of the neighbourhood park was within the observational range for parents. However, this was in stark comparison to children's mobility to the nearby market area. The market area, which was less than the $300 \mathrm{~m}$ distance from the neighbourhood, is perceived as unsafe by parents due to narrow street width, vehicular traffic and stranger danger. Children were mostly driven in cars or scooters here, but never alone.

"I drive my child in a car to this market, which is like 5 minutes walking distance (from my house). The reasons why I don't let her go alone is because she lacks confidence in crossing the road; secondly, there is unmanaged traffic, narrow street network, incidences of snatching (mobile, purse, gold chain etc.) and congested road. Such an environment is not what I consider safe for my child." (mother of a 10-year old girl)

\subsubsection{School Travels}

Private shared van was a popular mode of transport (60\%) to school followed by private car (30\%). Majority of these schools (45\%) were at a distance of 5-10 kilometres from the neighbourhood, with none of them providing bus services here, despite huge demand from parents. The other reason for the preference for private vans was their doorstep availability. However, issues of child's longer travel time and regular incidents of drivers ferrying more children than allowed remained a point of concern. It was also reported that many van drivers were dropping children few meters before school premises, forcing them to negotiate vehicular traffic all along the school entrance. The decade-old Delhi government's 'school cab policy 2007' was thus violated in many cases. As a result, a large number of parents were negative about even imagining their child commuting to school alone.

"Yes, I would suggest to parents that they should send them (children) by (school)bus, as buses are always better and safer. Because buses are the school's responsibility and they have to come every day. If there is a breakdown, immediately another bus has to take over. It does not happen with the van driver. Sometimes van driver waits for a particular child for a longer period, and because of that, other children get late (to school)." (father of an 11-yearold boy) 
Thus, parental concerns centred majorly around the child's safety and the collective belief in constant supervision of children. The longer commute distances to child-specific destinations further add a negative impact on parental attitude towards CIM.

\subsection{Children's perception of CIM}

A total of two themes emerged from the discussions with children on their viewpoint regarding independent mobility: (1) CIM within neighbourhood gates and (2) CIM outside neighbourhood gates.

\subsubsection{CIM within neighbourhood gates}

Majority of children (72\%) expressed satisfaction with the independent mobility levels granted to them within neighbourhood gates. They listed outdoor free play at the park, on-street play and pre-determined cycling route as daily activities conducted in accompaniment with other neighbourhood friends. Older children (10-12 years) enjoyed longer cycling routes within neighbourhood boundaries irrespective of gender. However, permissions to go alone to a friend's house were mainly granted to boys than girls. It was expected from children to give an acknowledgement call on the phone to their parents upon arrival at the destination. There were concerns especially raised by older children $(45 \%)$ related to fear of strangers and traffic. Since the neighbourhood shared boundaries and common services like the park and local street with neighbouring low-income localities, children narrated intimidating incidences with the residence of these localities, especially inside the park. Secondly, issues of on-street parking and speeding cars in late evenings on weekdays were other points of discomfort.

"I enjoy playing and cycling here. There is ample amount of space for my friends and me to spend our daily evenings after school. We play badminton, hop-scotch and even hide and seek behind these cars parked on the street. Although these cars reduce the overall playing area, we somehow manage to deal with it." (11-year old girl)

\subsubsection{CIM outside neighbourhood gates}

As mentioned earlier by parents, mobility outside neighbourhood gates for market, hobby or tuition class were dependent. Children, too, reported the same and were comfortable in being accompanied by adults to these destinations. Fear from strangers, lack of safe pedestrian sidewalk, vehicular traffic and noise pollution were some of the reasons attributed to the same. Children stated their desire to cycle alone to the market but, because of the above reasons, were not confident enough to do the same.

"We would like to cycle there (local market) but cannot do that because of so many cars that might hit us. It is a very busy road. Many people don't drive carefully, which is a major problem." (9-year old boy)

At the end of the session, children even provided some solutions to the identified problems, which included the installation of a security camera, separate cycle lane for older and younger children and strict restriction of vehicular speed within neighbourhood gates. 
Overall, for children, CIM is not a right but a non-negotiable permission level granted by parents depending upon their perception of location. Children provided a positive response towards the concept of CIM but agreed upon the restrictions imposed by parents keeping in view the fear of strangers and traffic.

\section{Discussion}

This paper initiates a dialogue of looking at CIM and UD as a complementary process overarching the aim of empowering children to move freely. By involving stakeholder participation, it informs about the on-ground challenges from an Indian urban context.

Drawing inferences from the findings of the first objective, it is evident that both CIM and UD, as concepts emerging from separate concerns and socio-political narratives, strives to achieve a common goal of social inclusion. In the case of UD, the agenda has always been to encompass all diverse sections of the society, while CIM focuses on children. However, the theoretical argument of CIM believes that child-friendly environments simultaneously caters to the needs of all, thus creating a binding factor with UD goals. Considering their beginnings in the $20^{\text {th }}$ century and their philosophical background, an argument can also be built upon the tremendous impact of the social model of disability as a guiding factor. Both CIM and UD looks at society as a disabling environment that needs to be re-designed or improvised for empowering its users. The focus on users is clear, as CIM strongly advocates for children to be a constant part of the process by having shared decisions with adults[38]. While UD being user-centric in its approach, mandatorily requires meaningful stakeholder participation. Further, unlike $\mathrm{UD}$, the relatively new CIM literature has majorly investigated upon its environmental influences than generating generalised guidelines or principles. One of the attributing reasons is the largely ignored diverse cultural aspect. It is here that UD can provide an opportunity for bringing in a cultural dimension into the discussion of children's social inclusion by independent mobility.

In India, the commitment towards creating child-friendly cities majorly comes under the country's 'Smart Cities' initiative. The existing guidelines and policy documents are largely based upon literature than field-based evidence from Indian cities. As a result, the focus is on conducting pilot-level spatial experiments using 'tactical urbanism'. The challenge of collecting data on children's actual mobility and inclusion of the parent's neighbourhood perception remains an unexplored subject.

The second objective explores both children and parent's perception regarding CIM. It supports previous research that safety from strangers and traffic are critical factors for both parents and children to limit or support CIM. Lack of nearby child-specific destinations and limited trust in public transport were two additional concerns expressed by parents that influence CIM levels. Children viewed CIM as parental permission-based than a right-based concept. One reason for this perception can be found within the general urban Indian parenting style, which has culturally been authoritative [39]. Unlike permission levels inside homes, mobility permissions for children were non-negotiable. Children expressed the desire to cycle freely outside neighbourhood gates but felt compelled due to reasons as mentioned above of traffic, strangers and parent's decisions.

The combined findings of the first two objectives lead us to the third one about improving CIM at a neighbourhood scale. UD as a theory and an applied concept can here play a vital role in enhancing inclusion by independence. Table 2 establishes a connection between existing barriers and proposed facilitators with overarching UD 
goals. It is argued that CIM, as an evaluating measure, can aid in using an appropriate UD strategy to create a safer and more inclusive neighbourhood.

Table 2. Barriers and facilitators at neighbourhood planning and policy level for CIM

\begin{tabular}{|c|c|c|c|}
\hline \multirow[t]{2}{*}{ S.No. } & \multicolumn{2}{|c|}{ Neighbourhood Planning and policy for CIM } & \multirow[t]{2}{*}{ UD Goals } \\
\hline & Existing Barriers & Proposed Facilitators & \\
\hline 1 & Fear of Traffic & $\begin{array}{l}\text { Safe pedestrian and cycling route } \\
\text { Separate lane for bicycle riders, } \\
\text { sidewalk, tabletop crossings and } \\
\text { strict vehicular speed regularisation } \\
\text { to enhance safety while prevention of } \\
\text { injury }\end{array}$ & $\begin{array}{l}\text { Goal no. } 2 \\
\text { (Comfort) and } \\
5 \text { (Wellness) }\end{array}$ \\
\hline 2 & $\begin{array}{l}\text { Fear of strangers and lack of } \\
\text { trust in children's } \\
\text { navigational skills }\end{array}$ & $\begin{array}{l}\text { Ease of navigation } \\
\text { Provision of child-friendly } \\
\text { neighbourhood maps and signages } \\
\text { created with meaningful children's } \\
\text { participation }\end{array}$ & $\begin{array}{l}\text { Goal no. } 3 \\
\text { (Awareness) and } \\
4 \\
\text { (Understanding) }\end{array}$ \\
\hline 3 & $\begin{array}{l}\text { On-street parking and } \\
\text { speeding vehicles inside } \\
\text { neighbourhood boundaries }\end{array}$ & $\begin{array}{l}\text { Barrier-free on-street play } \\
\text { Restriction on the number of car } \\
\text { ownerships and mandatory provision } \\
\text { of car parking space within } \\
\text { residential plots. High fees on on- } \\
\text { street parking. }\end{array}$ & $\begin{array}{l}\text { Goal no. } 6 \\
\text { (Social } \\
\text { Integration) and } \\
8 \text { (Cultural } \\
\text { Appropriateness) }\end{array}$ \\
\hline 4 & $\begin{array}{l}\text { Lack of nearby child-specific } \\
\text { destinations (school, } \\
\text { stationery shop, hobbies club, } \\
\text { structured sports class etc.) }\end{array}$ & $\begin{array}{l}\text { Distance to child-specific } \\
\text { destinations } \\
\text { Revisions in neighbourhood planning } \\
\text { policies for allocation of child- } \\
\text { specific destinations near residential } \\
\text { areas to attract 'groups' of children } \\
\text { travelling independently }\end{array}$ & $\begin{array}{l}\text { Goal no. } 7 \\
\text { (Personalisation) } \\
\text { and } 8 \text { (Cultural } \\
\text { Appropriateness) }\end{array}$ \\
\hline 5 & $\begin{array}{l}\text { Lack of trust in public } \\
\text { transport, areas around } \\
\text { stations and children's } \\
\text { navigational skills within } \\
\text { transit stations }\end{array}$ & $\begin{array}{l}\text { Diverse mobility options } \\
\text { Policies to improve } 800 \mathrm{~m} \text { buffer area } \\
\text { around transport/ transit stations, } \\
\text { especially catering to the needs of } \\
\text { children providing them with } \\
\text { multiple safe mobility options. }\end{array}$ & $\begin{array}{l}\text { Goal no. } 2 \\
\text { (Comfort) and } 7 \\
\text { (Personalisation) }\end{array}$ \\
\hline 6 & $\begin{array}{l}\text { Absence of direct } \\
\text { observational range from } \\
\text { residential plots to common } \\
\text { shopping area for constant } \\
\text { children's surveillance }\end{array}$ & $\begin{array}{l}\text { Informal social control } \\
\text { High land-use mix for higher 'eyes } \\
\text { on the street' to improve social } \\
\text { cohesion and parental trust }\end{array}$ & $\begin{array}{l}\text { Goal no.6 } \\
\text { (Social } \\
\text { Integration) and } \\
8 \text { (Cultural } \\
\text { Appropriateness) }\end{array}$ \\
\hline
\end{tabular}

The first step in this direction is to have separate lanes for both pedestrians and cycle users within neighbourhoods. It is essential, as noted in the study as well as on-field observations that children tend to walk alone or with adults to commute to the nearest locations. While cycling is seen as a leisure activity in the late evenings than a mode of transport. Both walking and cycling as an active mode of travel add to the physical activity levels of children and bridge connection with their local surroundings. Hence, it becomes extremely critical to create safe pedestrian and cycling zones by revising policies for vehicular speed regulations, provision of tabletop crossings, sidewalks and cycling lanes within neighbourhood boundaries. Such provisions directly align with the two UD goals of 'Comfort' and 'Wellness' as it caters to the limitations of the children's physical abilities while preventing any injury, which was a major fear among parents.

The second barrier emerges from the parental concern of children's navigational skills and maturity levels while independently moving and encountering strangers within 
local surroundings. One of the recommendations is to have co-created child-friendly city/neighbourhood maps and signages easily perceptible by children. For example, in the city of Boulder [40], a collaborative map creation process led to children experience higher independent mobility. Parents found the map as an asset to obtain information on the safe routes to various local destinations, including school. This process effectively communicates critical information to the users irrespective of age and physical abilities, thus assisting in achieving UD goals of 'Awareness' and 'Understanding'.

Among the various local destinations, the study revealed 'street' as one of the important places in children's daily routine. However, due to the absence of designated spaces for vehicular parking, residents tend to park their cars on-street, reducing the area for children's play and other outdoor activities. Despite many residential plots having basement parking facilities, on-street parking was an accepted norm resulting from the factors of convenience and availability of space. Moreover, rising car ownership per family was also an impediment to children's free mobility at a neighbourhood scale. A perspective shift is required in the overall parking models. Policy level changes like high fees for on-street parking, restricting car ownerships per family and mandatorily provision of parking spaces within residential plots can benefit in channelising a shifting trend. It is an example of accommodating the needs of everyone while catering to the existing cultural challenges, aligning with the UD goals of 'Social Integration' and 'Cultural Appropriateness'.

Moving forward, the study suggested that parents perceive 'groups' as safer and more reliable than 'individual' children while travelling to local destinations. So, with the provision of diverse child-specific destinations (like tuition, hobby or structured sports class) close to residential areas, more children accompanied with their friends will be encouraged to access these facilities independently. Considering these cultural perceptions, land-use zoning and neighbourhood planning policies should accommodate these needs supporting children's inclusion and independence to choose from a variety of nearby extra-curricular options. The UD goals of 'Personalisation' and 'Cultural Appropriateness 'clearly reflect this dimension.

The other notable factor was a complete lack of trust in public transport among parents. Public transport is not considered reliable or efficient for CIM in the majority of cities across the country. As mothers are considered the primary caregiver and nurturer of children [39], the mobility needs of children are usually seen from the angle of women's mobility needs. Usually, children in Indian metro cities are not considered as 'independent users' of public transport[41]. Public transport policymakers should address this gap by providing children with more mobility options catering to their specific requirements. UD goals of 'Comfort' and 'Personalisation' can assist in applied ways to incorporate opportunities for choice and expression of children's unique preferences while keeping in view their physical limits.

Lastly, considering parental fears and perception, strong support was seen towards higher 'informal social control' within the neighbourhood. In terms of planning, the neighbourhood's layout with a majority of residential plots facing the central park offered an advantageous viewing angle for parents. With a strong culture of interactions among neighbours, parents remained assured of their children being watched continuously by reliable people. However, the allowance of CIM towards common shopping area was low due to the lack of mutual trust between residents and shop-owners, along with the seclusion of the area far away from residential plots. It is proposed to have a higher land-use mix and resident's democratic control over the choice of shopping facilities within the neighbourhood. It will generate more 'eyes on the street' for indirect 
surveillance of their children. Application of this improvisation can assist in realising UD goals of 'Social Integration' and 'Cultural Appropriateness'.

\section{Conclusion}

In the past three decades, both CIM and UD have expanded within diverse disciplines of design, planning, policy and strategies. These concepts, which evolved parallelly, remain strongly rooted within a human-centric approach. While focusing on the influencing environmental factors on children's daily mobility, CIM has been majorly looked upon from a two-point perspective of planning and health (physical activity). This paper proposes the inclusion of a third perspective of 'culture' into the discussion by advancing a theoretical linkage with UD. As an integrated approach, UD offers an opportunity to not only have stakeholder's (children and parents) perspective into the discussion but also arrive at context-based solutions. At a neighbourhood scale, the application of UD principles and theories assists in creating a barrier-free and safe environment for mobility, treating all user groups, including children, equally and with dignity. When children are thus recognised as 'active users' of the built environment, it generates within them a sense of empowerment, belongingness and confidence to move independently.

The study opens a new direction of research within UD domain beyond education, mobility and play-activity needs of children with disabilities. Further research should consider different typologies of neighbourhoods and a large heterogeneous sample to broaden the understanding of the connection between CIM and UD.

\section{References}

[1] Hillman, M., Adams, J, Whitelegg, J, One false move: a study of children's independent mobility. 1990, Policy Studies Institute: London.

[2] Rissotto, A. and F. Tonucci, Freedom of movement and environmental knowledge in elementary school children. Journal of Environmental Psychology, 2002. 22(1-2): p. 65-77.

[3] Mackett, R., et al., Children's independent movement in the local environment. 2007. 33(4): p. 454468 .

[4] Ben Shaw, B.W., Bjorn Frauendienst, Andreas Redecker, Tim Jones, Mayer Hillman, Children's Independent Mobility: A comparative study in England \& Germany (1971 -2010). 2012, Policy Studies Institute: London, UK. p. 248.

[5] Schoeppe, S., et al., Australian children's independent mobility levels: secondary analyses of crosssectional data between 1991 and 2012. Children's Geographies, 2015. 14(4): p. 408-421.

[6] Witten, K., et al., New Zealand parents' understandings of the intergenerational decline in children's independent outdoor play and active travel. Children's Geographies, 2013. 11(2): p. 215 229.

[7] Appleyard, B.S., Can't Get There from Here: The Declining Independent Mobility of California's Children and Youth, in Surface Transportation Policy Project, Transportation and Land Use Coalition and Latino Issues Forum. 2003.

[8] Lam, W.W.Y., Loo, B.P.Y., Determinants of Children's Independent Mobility in Hong Kong. Asian Transport Studies, 2014. 3(2): p. 250-268.

[9] WHO, Global recommendations on physical activity for health. 2010: Geneva, Switzerland. p. 60.

[10] Katapally, T.R., et al., Results from India's 2016 report card on physical activity for children and youth. 2016. 13(11 Suppl 2): p. S176-S182.

[11] Malone, K., The bubble - wrap generation: children growing up in walled gardens. Environmental Education Research, 2007. 13(4): p. 513-527.

[12] Karsten, L., It all used to be better? Different generations on continuity and change in urban children's daily use of space. Children's Geographies, 2005. 3(3): p. 275-290. 
[13] Sharmin, S. and M. Kamruzzaman, Association between the built environment and children's independent mobility: A meta-analytic review. Journal of Transport Geography, 2017. 61: p. 104117.

[14] Marzi, I. and A.K. Reimers, Children's Independent Mobility: Current Knowledge, Future Directions, and Public Health Implications. Int J Environ Res Public Health, 2018. 15(11).

[15] Marzi, I., Y. Demetriou, and A.K. Reimers, Social and physical environmental correlates of independent mobility in children: a systematic review taking sex/gender differences into account. Int J Health Geogr, 2018. 17(1): p. 24.

[16] Steinfeld, E., Creating an inclusive environment, in Trends in Universal Design. 2013, Norwegian Directorate for Children, Youth and Family Affairs, The Delta Centre: Norway. p. 52-57.

[17] Carver, A., et al., A comparison study of children's independent mobility in England and Australia. Children's Geographies, 2013. 11(4): p. 461-475.

[18] Shaw, B., Bicket, Martha, Elliott, Bridget, Fagon-Watson, Ben, Mocca, Elisabetta, Hillman, Mayer, Children's Independent Mobility: an international comparison and recommendations for action. 2015, Policy Studies Institute: London. p. 92.

[19] Sallis, J.F., et al., An ecological approach to creating active living communities. 2006. 27: p. 297322 .

[20] Ostroff, E., Universal Design: An Evolving Paradigm, in Universal Design Handbook W. F.E.Preiser, H.Smith,K., Editor. 2011, McGarw-Hill. p. 1.3-2.0.

[21] Kose, S., How can the exploding senior population be accommodated? Japanese struggle towards inclusive design. Journal of Engineering Design, 2009. 21(2-3): p. 165-171.

[22] Bowe, F., Universal Design in Education: Teaching Nontraditional students. 2000, Westport, USA: Greenwood Publishing Group.

[23] Soltani, S.H.K., M.Y. Abbas, and M.B. Awang, Disabled Children in Public Playgrounds: A Pilot Study. Procedia - Social and Behavioral Sciences, 2012. 36: p. 670-676.

[24] Mullick, A., Inclusive indoor play: an approach to developing inclusive design guidelines. Work, 2013. 44 Suppl 1: p. S5-17.

[25] Goetz Ruffino, A., G.Mistrett,S.,Tomita,M.,Hajare,P., The Universal Design for Play Tool: Establishing Validity and Reliability. Journal of Special Education Technology, 2006. 21(4).

[26] Fernandes, T., Independent mobility for children with disabilities. International Journal of Therapy and Rehabilitation, 2006. 13(7): p. 329-33.

[27] Ross, T., Inclusive research design: Accounting for childhood disability in school transportation research, in Transportation and Children's Well-Being. 2020. p. 273-293.

[28] UNICEF, The situation of children in India: A profile. 2011: New Delhi.

[29] NIUA, Status of urban children in India: Baseline study 2018. 2018: New Delhi.

[30] MWCD, National plan of action for children, 2016. 2016, Government of India: New Delhi.

[31] NIUA, Indicators for child friendly local development I CHILD. 2016, National Institute of Urban Affairs: New Delhi.

[32] BVLF, Building Neighbourhoods to thrive in: Urban Planning, Design, Policy and evaluation for infants, toddlers and their caregivers in India_Design guidelines. 2018, BVLF, BDP: Delhi. p. 108.

[33] Ahmad, S., et al., Delhi revisited. Cities, 2013. 31: p. 641-653.

[34] Dupont, V., Socio-spatial differentiation and residential segregation in Delhi: a question of scale? Geoforum, 2004. 35(2): p. 157-175.

[35] Ahmad, S., Choi Joong, Mack, The context of uncontrolled urban settlements in Delhi ASIEN, 2011. 118: p. $75-90$.

[36] Bhonsle, K. and V. Adane, Assessing the Play Provisions for Children in Urban Neighborhoods of India: Case Study Nagpur, Maharashtra. Buildings, 2016. 6(3).

[37] Piaget, J., The construction of reality in the child. 1955: Routledge.

[38] A. Hart, R., Children's participation: From Tokenism to citizenship, in Innocenti Essays. 1992: Florence, Italy.

[39] Isaac, R., I.K. Annie, and H.R. Prashanth, Parenting in India, in Parenting Across Cultures. 2014. p. 39-45.

[40] Derr, V., et al., A City for All Citizens: Integrating Children and Youth from Marginalised Populations into City Planning. Buildings, 2013. 3(3): p. 482-505.

[41] Singh, S., Metro Matters: How to secure children in Delhi? Let's hear it from them, in Hindustan Times. 2017: New Delhi. 